\title{
OAM/A \\ AIAA 96-1859 \\ Assessment of Thermochemical Nonequilibrium and Slip Effects for Orbital Reentry Experiment (OREX)
}

R. N. Gupta, J. N. Moss, and J. M. Price

NASA Langley Research Center

Hampton, VA 23681-0001

\section{1st AIAA Thermophysics Conference June 17-20, 1996/New Orleans, LA}



Assessment Of Thermochemical Nonequilibrium and Slip Effects For Orbital Reentry Experiment (OREX)

by

Roop N. Gupta*, James N. Moss**, and Joseph M. Price***

NASA Langley Research Center

Hampton, VA 23681-0001

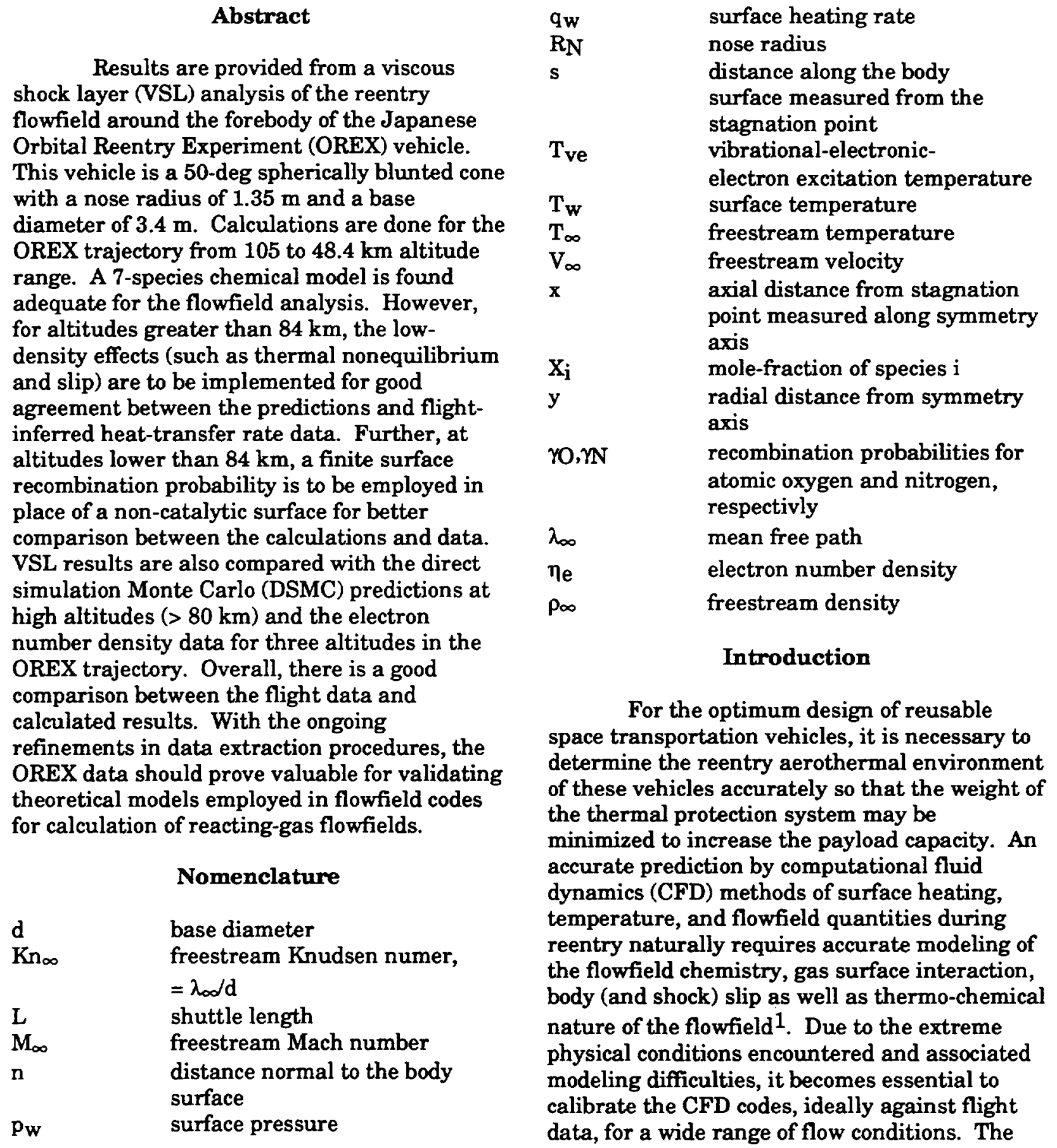

\footnotetext{
* Senior Research Engineer, Gas Dynamics Division, Associate Fellow AIAA.

** Senior Research Engineer, Gas Dynamics Division, Fellow AIAA.

*** Senior Research Engineer, Gas Dynamics Division.
} 
Orbital Reentry Experiment (OREX) was conducted recently by the Japanese ${ }^{2}$ from orbit to create such a data base to study the reentry technology and establish the reliability of computational design tools for Earth-Space Round Trip (ESRT) systems.

OREX was the first of the three flight experiments planned to obtain the technology base for the development of Japan's unmanned space shuttle called HOPE (H-II Orbiting Plane). OREX was launched into Earth Orbit by the H-II rocket on February 4, 1994, and was the first Japanese entry experiment. Two of many objectives of OREX were to: (i) gather reentry data (such as those for the aerodynamic and aerothermal environment and guidance/navigation/ control), and (ii) test the thermal protection system that has been developed for HOPE. For meeting the second objective, the maximum heating rate encountered by OREX was almost equal ${ }^{2}$ to that computed for HOPE. The initial reports ${ }^{2,3}$ provide an indication of the scope and quality of the basic data acquired.

The inferred surface heating rate data for OREX are considered potentially unique for altitudes above about $92 \mathrm{~km}$. Unlike the Shuttle Orbiter, which is an operational vehicle, OREX was enclosed in a protective fairing during launch thereby negates the requirement for waterproofing the thermal protection materials. Consequently, the OREX thermal protection system should not produce some of the outgasing products and the associated reduction ${ }^{4}$ in heating measured for the Orbiter during the initial phase of the heat pulse. A motivation, therefore, exists for the comparison of numerical predictions with the OREX data. Reference 3 presented a 7-species, onetemperature (1-T) analysis of the OREX stagnation-point heating data. The computations of Ref. 3 were recently redone 5 with new values for the thermal properties of the $\mathrm{C} / \mathrm{C}$ nose cap. The low-density effects (such as the thermochemical nonequilibrium and slip) were not considered in the analyses of Refs. 3 and 5 . In the data reduction procedure for the electrostatic probe ${ }^{2}$, however, a twotemperature (2-T) calculation method 6 was employed without the surface-slip effects.

In the present study, the OREX entry is analyzed by using the viscous shock-layer (VSL) technique of Ref. 1. This technique is used to calculate flowfield and surface quantities along the OREX forebody for altitudes of $105 \mathrm{~km}$ to $48.4 \mathrm{~km}$. Information concerning the surface temperature was obtained from Yamamoto ${ }^{5}$ for these altitudes. Comparisons of VSL results with flight data include stagnation-point heating rates and the flowfield electron number densities. An assessment of the low-density effects (such as thermochemical nonequilibrium and slip) on surface heating and flowfield quantities is made by comparison with the direct simulation Monte Carlo (DSMC) results obtained from the method of Bird ${ }^{7}$ and the flight data.

\section{Problem Definition and Methodology}

\section{OREX Geometry and Sensor Locations}

The OREX vehicle is a $50-\mathrm{deg}$

spherically blunted cone with a $1.35 \mathrm{~m}$ nose radius and a base diameter of $3.4 \mathrm{~m}$, as shown in Fig. 1(a). It was launched into Earth Orbit using Japan's new H-II launch vehicle. During entry, aerothermal data were obtained from about $120 \mathrm{~km}$ down to about $40 \mathrm{~km}$, including the blackout period when the maximum heating occurred.

Figure 1(b) shows a schematic of the various sensor locations on the exposed forebody of OREX, which consists of thermal protection materials that have been developed and are being evaluated for use on the HOPE vehicle. The nose cap is a monocoque carbon-carbon (C/C) nose having a thickness of $4 \mathrm{~mm}$. Surrounding the $\mathrm{C} / \mathrm{C}$ hot structure are twentyfour $\mathrm{C} / \mathrm{C}$ tiles $1.5 \mathrm{~mm}$ in thickness. The nose cap and the surrounding tiles are made from the same carbon-carbon mix. Ringing the $\mathrm{C} / \mathrm{C}$ tiles are some $\mathbf{2 3 0}$ ceramic tiles made of silicon-oxide and aluminum-oxide fibers connected to OREX's aluminum honeycomb shell. The ceramic tiles are $20 \mathrm{~mm}$ in thickness.

A few of the locations where measurements were made along the OREX forebody are also shown in Fig. 1(b). The measurements for which the data are compared with current VSL and DSMC calculations are:

(i) the inferred heating rates extracted ${ }^{8}$ from the back surface (with material thickness of $4 \mathrm{~mm}$ ) temperature measurements made at the nose cap stagnation point, and (ii) the electron number density distribution in the boundary 
layer measured by an electrostatic probe mounted on the conical flank before the probe shoulder. The electrostatic probe protrudes from the OREX vehicle surface $70 \mathrm{~mm}$ in height as shown in Fig. 1(c). Five semi-cylindrical electrodes of $0.2 \mathrm{~mm}$ diameter situated along the leading edge of the probe with $0.4 \mathrm{~mm}$ bluntness and $60^{\circ}$ sweep angle are numbered as shown in this figure. Those electrodes collect ions at 5 vertical positions to give the ion density profile in the boundary layer which is assumed equal to the electron number density to be measurable between $10^{16}-10^{20}$

electrons $/ \mathrm{m}^{3}$. The lowest altitude where the electron density measurement can be made within this range is about $75 \mathrm{~km}$. The procedure used to reduce the probe data is similar to that used with the RAM-C flight experiment ${ }^{9}$. Further details concerning the OREX flight measurements can be found in Ref. 2, 3, and 8 .

Computational Methods

The VSL method of Ref. 1 is used to analyze flowfields over the OREX forebody for altitudes from $105 \mathrm{~km}$ to $48.4 \mathrm{~km}$ and Mach numbers from 27.1 to 9.1), whereas the DSMC method of Bird ${ }^{7}$ is employed mostly at high altitudes (greater than about $80 \mathrm{~km}$ ) in the present study. The VSL method can be used to compute $^{1}$ reacting gas flows in thermochemical equilibrium or nonequilibrium state with and without body and shock-slip boundary conditions and with an arbitrary number of chemical species. For the current study, the number of species ranged from 5 to 11 using the VSL method while the DSMC method used herein considered only 5 species.

Detailed description of the VSL method used is given in Refs. 1 and 10. Briefly, this method is a spatial-marching, implicit, finitedifference technique, which includes coupling of the global continuity and normal momentum equations. For the thermal nonequilibrium calculations with two-temperatures, two energy equations are solved for the translationalrotational and vibrational-electronic-electron temperatures. Only, the total energy equation is needed to be solved for the thermal equilibrium calculations. Further, for the thermal nonequilibrium case, air chemistry is modeled by using a modified Arrhenius expression for the forward and backward rate coefficients (see Table 1 of Ref. 10). Chemical vibrational coupling is taken into account through the preferential dissociation and recombination model proposed by Park ${ }^{11}$. The body and shock-slip boundary conditions are implemented at higher altitudes in the OREX trajectory. A description of the thermodynamic and transport properties, chemical kinetics model with chemical-vibrational coupling, relaxation processes for the vibrationaltranslational and electronic-electrontranslational energies, and body and shock-slip boundary conditions is given in Refs. 1 and 10.

The surface is assumed to be noncatalytic in the present study for most of the calculations as suggested in Ref. 5. However, a finite catalytic wall boundary condition 1,12 (based on the Shuttle flight heat-flux measurements) is also implemented, which impacts the heating at altitudes lower than about $84 \mathrm{~km}$, At higher altitudes, finite wall catalycity does not affect heating much as compared to a noncatalytic surface. To obtain an estimate of the reduction in heating due to a noncatalytic (or finite catalytic) wall, some results are also obtained for a fully catalytic wall, which should be closer to the thermochemical equilibrium value.

The noncontinuum $2 \mathrm{D}$ /axisymmetric DSMC method, used to compute the results shown here, is described in Refs. 7 and 13 and is briefly discussed here. In this method, the molecular collisions are simulated using the variable hard sphere (VHS) molecular model. The collision cross-section is a function of the relative energy in the collision. Parameters used in the present study to define the VHS model are a reference temperature $(2880 \mathrm{~K})$, reference diameters for each of the five species $\left(3.062 \times 10^{-10}, 3.083 \times 10^{-10}, 2.297 \times 10^{-10}\right.$, $2.398 \times 10^{-10}$, and $3.065 \times 10^{-10} \mathrm{~m}$ for $\mathrm{O}_{2}, \mathrm{~N}_{2}, \mathrm{O}$, $\mathrm{N}$, and NO respectively), and the temperature exponent (set to 0.73) in the power law for viscosity coefficient. Energy exchange between the kinetic and internal modes is controlled by the Larson-Borgnakke statistical model. For the diatomic molecules, a rotational relaxation collision number of 5 and a vibrational relaxation collision number of 50 are used. The gas surface interactions are modeled by assuming the gas molecules to reflect diffusively with full thermal accommodation at the specified surface temperature. Similar to the 
VSL calculations, the finite catalytic wall boundary condition is imposed by using the surface recombination probabilities for atomic oxygen and atomic nitrogen inferred from Shuttle data 12 .

\section{Results and Discussion}

As described in the Introduction section, it is necessary for the computer codes with many models for simulating the physical processes to be validated against a wide range of flow conditions if these codes are to serve as useful design tools. Some of the codes show good accuracies against ground-test results, which, however, do not simulate high temperature real gas effects simultaneously as encountered in a flight. Thus, the code comparison against the flight data can not be over-emphasized, especially, for the high-energy flows.

This section provides details about the flight conditions for which calculations are made; the sensitivity of the calculated results to assumptions concerning flowfield chemistry, wall boundary conditions and freestream density; flowfield and surface quantities; comparisons of these quantities with flight measured data and, at higher altitudes, with direct simulation Monte Carlo (DSMC) method; and a brief discussion of the potential uniqueness of the OREX heating data set. Elight Conditions and Numerical Parameters

Table 1 provides the range of flight conditions considered, which encompass altitudes of $105 \mathrm{~km}$ to $48.40 \mathrm{~km}$. Figure 2 shows the atmospheric (freestream) density from three different sources for this altitude range. The atmosphere values denoted as OREX are those given by Yamamoto 3,5 for which he has performed Navier-Stokes calculations. These values are similar to those for the 1962 U.S. Standard Atmosphere ${ }^{14}$ up to an altitude of about $90 \mathrm{~km}$. For altitudes above $90 \mathrm{~km}$, the atmospheric properties given by Jacchia 15 (for an exospheric temperature of $1200 \mathrm{~K}$ ) are employed. Jacchia values have been used extensively in previous high-altitude studies ${ }^{16}$, 17. These values are different than those given by the OREX atmosphere ${ }^{3}$ and avoid a significant change in the slope of the densityversus-altitude curve around $90 \mathrm{~km}$ altitude (see Fig. 2). The density values from the Jacchia atmosphere are lower by about one-third from those given by Yamamoto (see Table 1) at higher altitudes.

The stagnation-point temperatures (see Table 1) and surface temperature distributions (see Fig. 3(a)) employed in the present study are those obtained by Yamamoto 5 for altitudes of $105 \mathrm{~km}$ and below using a Navier-Stokes solution for the flowfield coupled with a material response code as described in Ref. 3 . The considerable temperature variations shown in Fig. 3(a) are due to variations in materials, material thicknesses, and material thermal properties. The carbon-carbon nose cap with a thickness of $0.4 \mathrm{~mm}$ extends to a wetted length of $\mathrm{s}=\mathbf{0 . 9 4 2} \mathrm{m}$ (measured from the stagnation point). Following the nose cap are the carboncarbon tiles which terminate at $\mathrm{s}=\mathbf{1 . 2 4 2} \mathrm{m}$ and then four rings of silica tiles, having much lower conductivities and hence higher surface temperatures, extend to $s=1.982 \mathrm{~m}$. The corner shoulder is also protected with a fifth ring of silica tiles. Figure 3(b) shows a comparison of the history of calculated values and flight data for the rear surface stagnation-point temperature. The computations of Ref. 5 for the surface temperature are different from those of Ref. 3 for two reasons: (i) thermal properties of the $\mathrm{C} / \mathrm{C}$ nose cap are changed to new values, and (ii) internal emission from the $\mathrm{C} / \mathrm{C}$ nose is assumed to be zero by the heat shield effects, as recommended by the industry. These two changes result in a $\mathrm{C} / \mathrm{C}$ nose cap temperature history, calculated by the coupled NavierStokes/material response (CFD-FEM) code, to agree better with the flight temperature history for the altitude range of $105 \mathrm{~km}$ to $45 \mathrm{~km}$.

The VSL calculations have been made by using a normal grid with 101 points, which are clustered both at the body surface and shock to capture large gradients in the flow properties there at low densities. The points are clustered only at the body surface at higher densities. The grid spacing is varied from $1 \times 10^{-6} \mathrm{~m}$ to $1 \times 10^{-4} \mathrm{~m}$ to obtain a grid-independent solution for the altitude range given in Table 1 . The smallest grid is used at the lowest altitude of $48.40 \mathrm{~km}$ and is increased in inverse proportion to the density for higher altitudes. In the streamwise direction, a minimum grid spacing of $2 \times 10^{-2} \mathrm{~m}$ is used.

For the DSMC calculations ${ }^{13}$, the size of computational cells adjacent to the body surface 
in the direction normal to the surface is usually less than half of the local mean free path length, and for most solutions much smaller. Previous experience ${ }^{16}$ has shown that such a resolution adjacent to a surface provides results that are independent of further cell refinement. For the lower altitude cases, the computational cells had very large aspect ratios with the dimensions along the surface equal to many local mean free path lengths.

Elowfield and Surface Quantities

This section gives results from the detailed VSL calculations for flowfield and surface quantities at altitudes of $92.82,88.45$, 84.01 , and $59.60 \mathrm{~km}$ (peak-heating altitude in Ref. 3). These results are later compared extensively with the flight data for electron density and stagnation-point heating. Presented results in this section include an assessment of the thermal nonequilibrium (i.e. 2-T v/s 1-T predictions) and slip effects on flowfield and surface quantities at these altitudes and on stagnation heating along the entire flight trajectory. A comparison of the VSL results is also made with the Navier-Stokes calculations of Yamamoto ${ }^{5}$, and the present direct simulation Monte Carlo computations. Before comparing the present results with other calculations and flight data, however, it is useful to have an indication of the sensitivity of the VSL calculations to various parameters that are employed to define the problem. Some of the parameters considered are the number of species in the chemistry model, surface catalytic activity, and freestream density. A variation in the values of these parameters gives an indication of the sensitivity of computed results to the uncertainty in their specified values. The sensitivity study has been done for altitudes of $92.82,88.45$, and $59.60 \mathrm{~km}$ except for the chemistry model, which is studied by employing the freestream and surface conditions considered at the US-European Conference ${ }^{18}$ on high speed flowfields.

Sensitivity to Number of Species in a Chemistry Model. Figure 4 shows the stagnation heating for a noncatalytic surface for two-temperature (2-T), 5 -species $\left(\mathrm{O}, \mathrm{O}_{2}, \mathrm{~N}, \mathrm{~N}_{2}\right.$, and $\mathrm{NO}), 7$-species $\left(\mathrm{O}, \mathrm{O}_{2}, \mathrm{~N}, \mathrm{~N}_{2}, \mathrm{NO}, \mathrm{NO}^{+}\right.$, and $\left.\mathrm{e}^{-}\right)$, and 11-species $\left(\mathrm{O}, \mathrm{O}_{2}, \mathrm{~N}, \mathrm{~N}_{2}, \mathrm{NO}, \mathrm{O}^{+}, \mathrm{O}_{2}{ }^{+}\right.$, $\mathrm{N}^{+}, \mathrm{N}_{2}+, \mathrm{NO}^{+}$, and $\left.\mathrm{e}^{-}\right)$chemistry models. For the altitude $(91.86 \mathrm{~km})$ considered, surface and shock-slip are found to influence the surface heating more significantly than the number of species in the chemistry model. The effect on surface heating is negligible when the number of species is increased from 7 to 11 . Therefore, a 7-species chemistry model is considered adequate for the present study.

Sensitivity to Surface Catalytic Activity. The surface heating calculations are made with the assumptions of noncatalytic, finite catalytic, and fully catalytic walls. The finite catalytic surface recombination values employed are those of Ref. 12. The VSL prediction using these values are compared with the STS-2 data (Ref. 19) in Fig. 5. For the 92.82 and $84.01 \mathrm{~km}$ altitude results shown in Figs. 6(a) and 6(b), the surface temperatures are less than about $1100 \mathrm{~K}$ and the recombination probabilities for the finite catalytic wall in these figures are less than $3.25 \times 10^{-3}$ and $9.35 \times 10^{-4}$ for atomic oxygen and nitrogen, respectively. With these low values of the recombination probabilities, the calculated heat transfer rates are essentially the same as those for the noncatalytic wall case. However, at $59.60 \mathrm{~km}$ altitude (see Fig. 6(c)), the maximum recombination probability values for atomic oxygen and nitrogen increase to $2.20 \times 10^{-2}$ and $1.50 \times 10^{-3}$, respectively, at the stagnation point where the temperature is about $1460 \mathrm{~K}$. For a noncatalytic wall, a $34 \%$ reduction in stagnation VSL heating prediction is obtained for this case. However, for a fully catalytic wall this heating rate is increased by about 31\%. For $92.82 \mathrm{~km}$ altitude (Fig. 6(a)) also, the VSL heating rates for the fully catalytic wall condition are larger, substantially so for the $84.01 \mathrm{~km}$ altitude case (Fig. 6(b)), as compared to the noncatalytic (or finite catalytic) wall values. It may be mentioned here that the VSL calculations at higher altitudes (Figs. 6(a) and 6(b)) employ a two-temperature (2-T) formulation with surface and shock-slip boundary condition and a one-temperature (1-T) model with no-slip boundary condition at lower altitudes (Fig. 6(c)) to reflect appropriate flowfield physics in the computations.

Figures 6(a)-6(c) also contain the onetemperature (1-T) Navier-Stokes calculations of Yamamoto 5 for a noncatalytic wall with zero surface slip. Also shown in these figures are the OREX stagnation inferred flight data for comparison. Present VSL calculations for a finite-catalytic wall are in good agreement with 
reported flight data as shown for altitudes of 92.82 and $59.60 \mathrm{~km}$ (Fig. 6(a) and 6(c)). At $84.01 \mathrm{~km}$ altitude (Fig. 6(b)), however, these calculations are lower by about $17 \%$ as compared to the data. Assuming the surface to be noncatalytic at lower altitudes will result in lower heating as compared to the inferred flight data as seen from Fig. 6(c). The Navier-Stokes calculations of Ref. 5 also give surface heating distributions, which appear at variance (see Figs. 6(a) and 6(c), for example) with the catalytic boundary condition employed in the present calculations.

Sensitivity to Freestream Density. Actual atmospheric density during reentry can be a significant uncertainty for a given altitude/time, particularly at the higher altitudes. It may differ significantly from that obtained from a standard atmospheric model ${ }^{14}$, 15. The significance of this effect on surface heating is shown in the 'Comparison with Flight Data' section later.

Assessment of Thermochemical Nonequilibrium and Slio Effects. An evaluation of thermochemical nonequilibrium in the flowfield can be made by analyzing the temperature profiles and surface distributions of pressure and heating rate for a non-catalytic wall. Figures 7(a) and 7(b) show stagnation profiles for the translational-rotational $(T)$ and vibrational-electronic-electron ( $\left.\mathbf{T}_{\mathbf{v e}}\right)$ temperature ratios for altitudes of 92.82 and $84.01 \mathrm{~km}$, respectively. At $92.82 \mathrm{~km}$ altitude (Fig. 7(a)), the two temperature ratios are quite different through the entire shock layer and accordingly, thermal nonequilibrium extends all the way to the surface. The degree of nonequilibrium in the two temperature profiles, however, is much reduced closer to the surface at $84.01 \mathrm{~km}$ altitude as shown in Fig. 7(b). Effects of thermal nonequilibrium on surface quantities may be evaluated by analyzing the pressure distributions given in Figs. 8(a) and 8(b). Unlike the continuum calculations, where assumptions are made with regard to the pressure tensor, a DSMC calculation accounts for nonisotropic effects which become significant under rarefied (thermal nonequilibrium) conditions. Therefore, normal force per unit area is shown in these figures from the DSMC calculations for comparison with the surface pressure $\left(p_{w}\right)$ distribution obtained from the VSL computations. Under thermal equilibrium conditions, the isotropic pressure $\mathrm{pw}_{\mathrm{w}}$ and normal force per unit area can be identified to be the same ${ }^{7}$. The surface distributions of these two quantities are different at the altitude of $92.82 \mathrm{~km}$ (Fig. 8(a)) suggesting the influence of thermal nonequilibrium on surface pressure, $\mathrm{p}_{\mathrm{w}}$, which is increased by about $20 \%$. At $84.01 \mathrm{~km}$ altitude (Fig. 8(b)), however, distributions of normal force/area and $p_{w}$ essentially have the same values, which imply conditions closer to thermal equilibrium.

To assess the effect of thermal nonequilibrium on surface heating rate at $84.01 \mathrm{~km}$ altitude, heating-rate distributions are computed (Fig. 9) using 1-T (for thermal equilibrium) and 2-T (for thermal nonequilibrium) models with the VSL method. Also, results are obtained with and without shock and surface-slip conditions. As shown in Fig. 9, the VSL results imply that the effects of both thermal nonequilibrium (even though present to some extent within the shock layer (Fig. 7b)) and slip are insignificant on surface calculated quantities for the $84.01 \mathrm{~km}$ altitude conditions and these effects may be neglected in calculations below this altitude. Comparison with Direct Simulation Monte Carlo (DSMC) and Navier-Stokes (NS) Calculations. Surface heating-rate distributions obtained using the VSL method are compared with those obtained from DSMC and NS calculations in Figs. 10(a) and 10(b) at altitudes of 92.82 and $84.01 \mathrm{~km}$, respectively. Also shown are the flight inferred data for the stagnationpoint heating. Except for the results shown over the conical flank in Fig. 10(a), there is generally a good agreement between the VSL and DSMC calculations for the two altitudes (Figs. 10(a) and $10(\mathrm{~b})$ ). This implies that a 2-T VSL formulation with slip boundary conditions models the low-density effects (thermal nonequilibrium and slip) quite well. The NS calculations of Ref. 5 are also in good agreement with the present results in the stagnation region at $92.82 \mathrm{~km}$ altitude (Fig. 10(a)) and along most parts of the OREX forebody at $84.01 \mathrm{~km}$ altitude (Fig. 10(b)). It is not obvious, however, why the NS results of Ref. 5 away from the stagnation region are higher in Fig. 10(a). Generally, the influence of a shoulder expansion on the upstream surface heating should become negligible at higher altitudes. The surface 
heating becomes a function of only surface inclination at free molecular flow conditions. Present calculations agree quite well with the stagnation flight data at $92.82 \mathrm{~km}$ altitude. However, the present results are lower than the flight data by about $17 \%$ at $84.01 \mathrm{~km}$ altitude. Also, some slip effects are noticeable over the conical flank at this altitude

(Fig. 10(b)).

Additional comparisons of the present results with DSMC and NS calculations and flight data at the stagnation point are shown in the next section.

Comparison with Elight Data

This section provides a comparison between the computed and flight-inferred stagnation-point heating rates and electron number densities (measured from the electrostatic probe mounted near the shoulder of the vehicle).

Stagnation-Point Heating. Figures 11(a) through 11(c) present VSL results (for altitudes of 105 to $48.4 \mathrm{~km}$ ) as function of flight time from launch. The DSMC calculations for altitudes of 105 to $79.9 \mathrm{~km}$ are shown in Fig. 11(c). Also shown in Figs. 11(a) and 11(c) are the NS calculations (called CFD-FEM results in Ref. 3) of Yamamoto 5 .

The NS results of Refs. 3 and 5 were obtained with the thin-layer Navier-Stokes equations coupled with a finite-element modeling (FEM) solver that models the heattransfer within the thermal protection material and provides the wall temperature boundary condition for the Navier-Stokes solver. The FEM solver accounted 3 for both temperature and directional property dependence of the thermal protection materials considered. An outline of the coupling procedure between the NS and FEM solvers is given in Ref. 3 . The NS results employed the following modeling features: no-slip and noncatalytic surface boundary conditions, and a one-temperature (1-T), 7-species nonequilibrium chemistry model. The unpublished results of Ref. 5 (used in the present work for comparison) were obtained recently and differ from those reported in Ref. 3 in that the agreement between the computed and flight-measured back surface temperature was improved for the reasons mentioned earlier.

The inferred flight data shown in Fig. 11 (and earlier) are taken from Ref. 3 and are referred to as 'inferred from flight'. The procedures used to obtain these data are described in Ref. 8.

Since atmospheric data was not gathered during the OREX flight experiment, calculations of Refs. 3 and 5 are based on the atmospheric conditions given in Ref. 3 , which is referred to as "OREX Atmosphere" in Figs. 11(a) and 11(b) and in Table 1. Also shown in these two figures are the VSL calculations based on the 'Jacchia Atmosphere' model ${ }^{15}$ for altitudes above $90 \mathrm{~km}$ (see Table 1 for the two models). As can be seen from Fig. 11(a), the 2-T VSL predictions for a noncatalytic wall (with slip) based on the Jacchia atmosphere are in better agreement with inferred flight data between the 90 and $105 \mathrm{~km}$ altitude range as compared to both the NS and VSL calculations utilizing the OREX atmospheric data. Further, the effect of slip on surface heating is dominant, whereas the thermal nonequilibrium (2-T) effects are secondary in this altitude range. Both slip and thermal nonequilibrium (2-T) effects are neglected in the NS

calculations 3,5 .

For altitudes below $84.01 \mathrm{~km}$, surface temperatures are higher and slip and thermal nonequilibrium effects become negligible. At higher temperatures, finite surface catalytic activity also begins to influence the heating rate. Therefore, a one-temperature (1-T), noslip, and finite catalytic wall flow model is appropriate for the lower altitude calculations. The VSL calculations with these flow assumptions are in better agreement with the inferred flight data than the 1-T, no-slip, noncatalytic VSL and NS calculations as shown in Fig. 11(a). The dotted line in Fig. 11(b) is a fairing through the VSL predicted values with appropriate flow physics from high-to-low flight altitudes. As mentioned earlier, the low-density (i.e. slip and thermal nonequilibrium) effects become negligible for the OREX forebody surface results at an altitude of about $84 \mathrm{~km}$. Figure 11(c) shows a comparison between VSL (with appropriate physics), NS, and DSMC predictions and with the inferred flight data. The DSMC results are shown for the high-altitude range of 105 to $79.9 \mathrm{~km}$. Overall, the qualitative behavior of the DSMC results is similar to that of VSL calculations and there is a good agreement between the two and with the inferred flight data. The NS (1-T, no 
slip, NCW) calculations of Yamamoto 5 are higher for altitudes greater than $88.45 \mathrm{~km}$ as compared to the VSL and DSMC calculations as well as the inferred flight data. As explained earlier, non-inclusion of thermal nonequilibrium and slip effects at higher altitudes and nonimplementation of finite-catalytic wall boundary condition at lower altitudes with the NS computations 3,5 may be responsible for the differences with the VSL and DSMC predictions. As described in the Introduction section earlier, the OREX vehicle was enclosed in a protective fairing during launch, thereby negating the requirement for waterproofing the thermal protection materials. Since the Shuttle Orbiter, is an operational vehicle, waterproofing procedures are employed. Therefore, the OREX thermal protection system should not produce some of the outgasing products and consequent reduction in heating that is evident for the Orbiter ${ }^{4}$ during the initial portion of the heat pulse. The surface heat-transfer coefficient based on the initial entry heating data reported for OREX exhibits ${ }^{13}$ a monotonic increase with the increase in Knudsen number. This type of behavior is characteristic 20,21 of the hypersonic cold-wall, stagnation-point heating for a nonblowing surface.

Electron Number Density. Flight data for the electron number density distribution in the boundary layer with strong entropy layer swallowing serve to delineate the applicability of 'two-temperature (2-T)' and 'one-temperature (1-T)' flow models for nonequilibrium ionized gas flows. An accurate calculation of the electron density also provides knowledge of the onset and expiration of the communication 'black-out' phase during entry.

Figures 12(a)-12(c) show the electron number density history at positions where probes 1, 3, and 5 (see Fig. 1(c)) are located. Two sets of data shown in these figures are reduced 2,5 by using 1-T and 2-T CFD methods of Ref. 6, which employs Navier-Stokes equations with a 7-species chemical model and Park's ${ }^{11}$ two-temperature model for the 2-T calculations. Also shown in these figures are predictions from these calculations reported in Ref. 2. Since the signal conditioner of the electrostatic probe is adjusted to measure the electron density in the $10^{16}-10^{20}$ particles $/ \mathrm{m}^{3}$ range, there are no data measured for Probe 1 between the flight times of 7401 and 7411 seconds as shown in Fig. 12(a). It is not obvious, however, why the electron density first decreases at a flight time of about $7391 \mathrm{~s}$ and increases again at about $7421 \mathrm{~s}$ for Probe 1 location. Similar decrease and increase in data is noticed for Probe 2 (not shown here) and Probe 3 (see Fig. 12(b)) also at different times in flight ${ }^{5}$. Figure 12(c) shows a continuous increase in electron density for Probe 5 with the increasing flight time (or decreasing altitude) as expected.

Present VSL calculations are given at the three altitudes of $92.82,88.45$, and $84.01 \mathrm{~km}$ or the flight times of 7391, 7401, and 7411.5, respectively, in Figs. 12(a)-12(c). These calculations are done with 1-T and 2-T flow models and slip boundary conditions. Present 1-T VSL predictions are slightly higher than the 2-T VSL results. Both of these VSL calculations are closer to the data and 1-T CFD calculations than the 2-T CFD results for all the three probe locations shown in Figs. 12(a)-12(c). Similar to the surface heating results given earlier, the effect of thermal nonequilibrium on electron density also appears to be secondary. The observation of Ref. 2 that the flight data agree better with 1-T flow model is not necessarily the case for the present calculations. For flight times earlier than $7401 \mathrm{~s}$ (i.e. at higher altitudes), when the low-density effects (such as thermal nonequilibrium and slip) become important, a 2-T flow model with slip should be more realistic as evidenced by the good agreement between the 2-T VSL and DSMC calculations shown earlier.

Finally, Figs. 13(a)-13(c) show further detailed comparisons between the predicted values and data for the electron density profiles at the altitude of $84.01 \mathrm{~km}$ for the three probe locations. The VSL predictions in these figures have been obtained with the assumptions of thermal nonequilibrium (2-T) and equilibrium (1-T) with and without the slip boundary conditions. Except for the narrow region near the shock, the electron density profiles (similar to the surface heat-transfer rates) are predicted essentially by the thermal-equilibrium, no-slip flow model for the three probe locations. Except for Probe 1 (Fig. 13(a)), the electron density profiles pass through the flight-measured values for Probes 3 and 5 as shown in Figs. 13(b) and 13(c). As noticed in Fig. 12(a) earlier, the reason 
for the low flight values for Probe 1 as compared with the calculations is not obvious. Further, present VSL predictions are in good agreement with the NS results ${ }^{2}$ at this altitude for all the three probes.

\section{Summary and Conclusions}

This study presents a viscous shocklayer (VSL) analysis of the reentry flowfield around the forebody of the Japanese Orbital Reentry Experiment (OREX) vehicle. The OREX vehicle is a 50-deg half-angle spherically blunted cone with a nose radius of $1.35 \mathrm{~m}$ and a base diameter of $3.4 \mathrm{~m}$. Obtained results span an altitude range of 105 to $48.4 \mathrm{~km}$. In this altitude range, the flowfield character changes from thermal nonequilibrium to thermal equilibrium and the slip effects become insignificant at lower altitudes. The low density effects (such as thermal nonequilibrium and slip) at higher altitudes in the VSL method are accounted for through the two-temperature (2-T) formulation with slip boundary conditions. With the disappearance of these effects at lower altitudes, VSL results are computed from onetemperature (1-T) flow model with no-slip boundary conditions. Within the altitude range considered, the influence of low-density and the surface catalycity effects on flowfield structure is analyzed in detail. Present results are compared with the flight data and existing Navier-Stokes (NS) calculations for the OREX trajectory, and with the direct simulation Monte Carlo (DSMC) results at higher altitudes in this trajectory.

Results from sensitivity studies indicate that a 7-species chemical model is adequate to analyze the OREX flowfield. However, the inclusion of low-density effects (i.e. both thermal nonequilibrium and slip) is important for altitudes greater than $84 \mathrm{~km}$. This is demonstrated by the comparison of viscous shock-layer results obtained from onetemperature, no-slip and two-temperature, slip flow models. Surface catalytic activity also significantly influences the level of heating at altitudes lower than $84 \mathrm{~km}$ in the trajectory. At the peak heating altitude of $59.60 \mathrm{~km}$, a $50 \%$ reduction in heating is obtained for a noncatalytic wall as compared to a fully catalytic wall. Reduction in heating is about $23 \%$ for a finite-catalytic surface with recombination probabilities similar to those of the Shuttle Orbiter thermal protection coatings. However, at higher altitudes, the recombination probabilities are quite low and the calculated heating for altitudes greater than about $84 \mathrm{~km}$ is essentially the same as that for a noncatalytic surface.

Since atmospheric data were not gathered in the OREX flight experiment, sensitivity of the atmospheric data used in earlier Navier-Stokes calculations is evaluated by employing the Jacchia atmospheric model for altitudes greater than $90 \mathrm{~km}$. Generally, a better agreement between the VSL predictions and flight heating data is obtained using the Jacchia values.

In general, there is a good agreement between the VSL predictions and the OREX measured or inferred data for electron number density and stagnation-point heat-transfer rate. Present results compare quite well with the direct simulation Monte Carlo (DSMC) predictions for altitudes higher than about $84 \mathrm{~km}$. The earlier Navier-Stokes calculations are higher at high altitudes due to the noninclusion of low-density effects and lower at low altitudes due to the use of non-catalytic wall boundary conditions when compared with the flight-inferred heat-transfer rate data.

The OREX heat-transfer rate data may be unique for high-altitude flight conditions in that they exhibit proper qualitative behavior with increasing altitudes. With further refinements in data extraction procedures and definitions, a valuable aerothermodynamic data base will become available. This data base should prove immensely helpful in validating the use of various theoretical models used for simulation and provide a test of flowfield codes for reacting gas flows.

\section{References}

${ }^{1}$ Gupta, R. N., "Viscous Shock-Layer Study of Thermochemical Nonequilibrium," Journal of Thermophysics and Heat Transfer, Vol. 10, No. 2, 1996, pp. 257-266.

${ }^{2}$ Inouye, Y., "OREX Flight-Quick Report and Lessons Learned," Invited paper 4, 2nd European Symposium on Aerothermodynamics of Space Vehicles, ESTEC, Nov. 1994. 
3Yamamoto, Y. and Yoshioka, M., "CFD and FEM Coupling Analysis of OREX Aerothermodynamic Flight Data," AlAA Paper 95-2087, June 1995.

${ }^{4}$ Moss, J. N. and Bird, G. A, "Direct Simulation Transitional Flow for Hypersonic Re-entry Conditions," Progress in Astronautics and Aeronautics: Thermal Desien of Aeroassisted Orbital Vehicles, edited by H. F. Nelson, Vol. 96, 1985, pp. 113-139.

5Yamamoto, Y., private communication, Aerodynamics Division, National Aerospace Lab., Tokyo-182, Japan, Dec. 1995.

${ }^{6}$ Watanabe, Y., Inouye, Y., Wada Y., Akimoto, T., and Fujiwara, T., "Computational and Experimental Studies on an Electrostatic Probe and Catalytic Effect Sensor for a Reentry Experiment," AIAA Paper 93-0479, Jan. 1993.

${ }^{7}$ Bird, G. A, "Molecular Gas Dynamics and the Direct Simulation of Gas Flows," Clarendon Press, Oxford, 1994.

8NAL/NASDA Joint Research Report. OREX, March 1995 (in Japanese).

${ }^{9}$ Jones, W. L., Jr., and Cross, A. E., "Electrostatic Probe Measurements of Plasma Parameters for Two Reentry Flight Experiments at 25000 Feet Per Second," NASA TN D-6617, April 1972.

${ }^{10}$ Gupta, R. N. and Lee, K. P., "Thermochemical Nonequilibrium Analysis of Viscous Shock-Layers," AIAA Paper 95-2083, June 1995.

11 Park, Chul, "Nonequilibrium Aerothermodynamics," Wiley, New York, 1990 , pp. 103-115.

${ }^{12}$ Gupta, R. N., "Reevaluation of FlightDerived Surface Recombination-Rate Expressions for Oxygen and Nitrogen," Journal of Spacecraft and Rockets, Vol. 34, No. 1, Jan. Feb. 1997.
13Moss, J. N. and Price, J. M., "DSMC Calculations for OREX Entry and Comparison with Flight Measurements in the Transitional Flow Regime," To appear as NASA TM, 1996.

14 Anon., U.S. Standard Atmosphere, U.S. Government Printing Office, Washington, DC, Dec. 1962.

15Jacchia, L. C., "Thermospheric Temperature, Density and Composition: New Modes," Research in Space Science, Smithsonian Institution Astrophysical Observatory, SAO Special Report 375, Cambridge, MA, March 1977.

${ }^{16}$ Celenligil, M. C., Moss, J. N., and Blanchard, R. C., "Three-Dimensional Rarefied Flow Simulations for the Aeroassist Flight Experiment Vehicle," AIAA Journal, Vol. 29, No. 1, Jan. 1991, pp. 52-57.

${ }^{17}$ Gupta, R. N., "Stagnation Flowfield Analysis for an Aeroassisted Vehicle," Journal of Spacecraft and Rockets, Vol. 30, No. 1, Jan. Feb. 1993, pp. 14-21.

18US-European Conference on High Speed Flow Fields, Dept. of Mathematics, University of Houston, Texas, November 1995.

${ }^{19}$ Throckmorton, D. A., "Benchmark Aeroheating Data From the First Flights of the Space Shuttle Orbiter," AIAA Paper 82-0003, Jan. 1982.

20 Gupta, R. N. and Simmonds, A. L., "Hypersonic Low-Density Solutions of the Navier-Stokes Equations with Chemical Nonequilibrium and Multicomponent Surface Slip," AIAA Paper 86-1349, June 1986.

${ }^{21}$ Moss, J. N.; Cuda, V., Jr.; and Simmonds, A L., "Nonequilibrium Effects for Hypersonic Transitional Flows," AIAA Paper 87-0404, Jan. 1987. 
Table 1. Flight Trajectory for OREX vehicle.

(a) Freestream Conditions

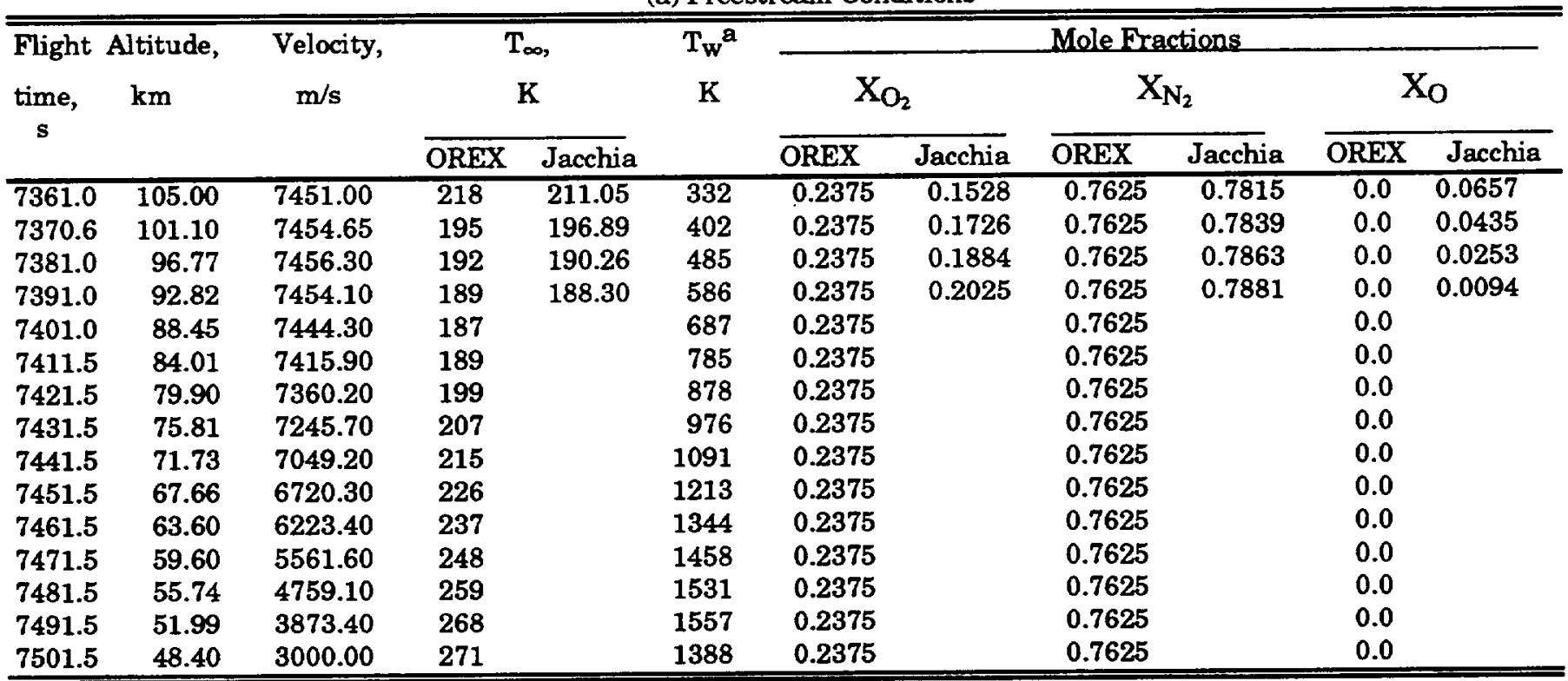

${ }^{a_{C}}$ FD inferred stagnation surface temperatures of Yamamoto (Ref. 5). Also, temperature distributions are specified from the same CFD computations.

Table 1. Concluded.

(b) Freestream Conditions

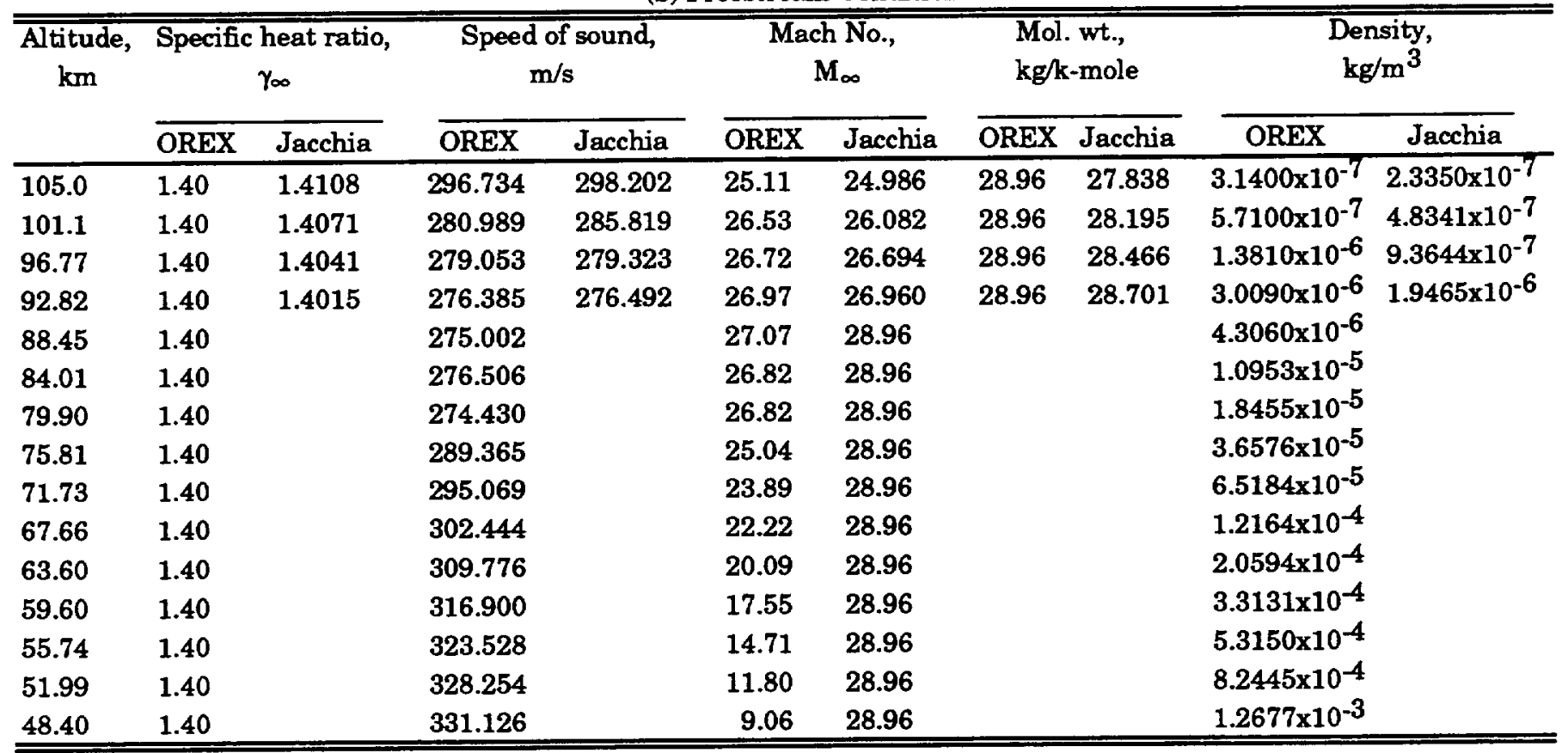




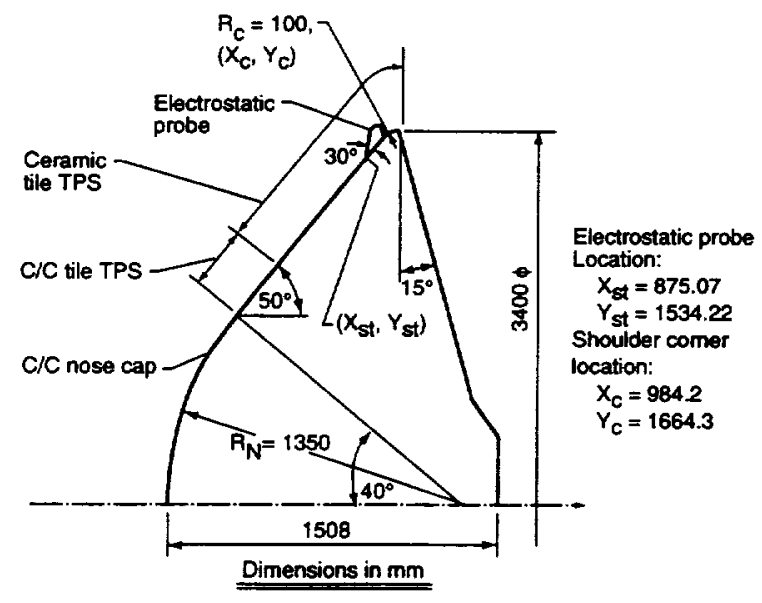

(a) Reentry body geometry (50-deg Sphere Cone)

Fig 1 OREX Vehicle.

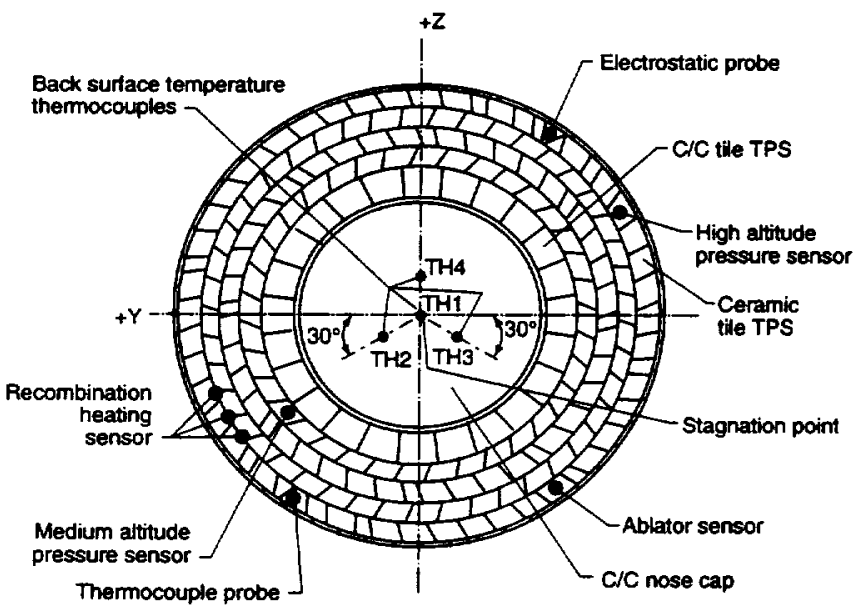

(b) Frontal View of OREX With Sensor Locations

Fig. 1 Continued.

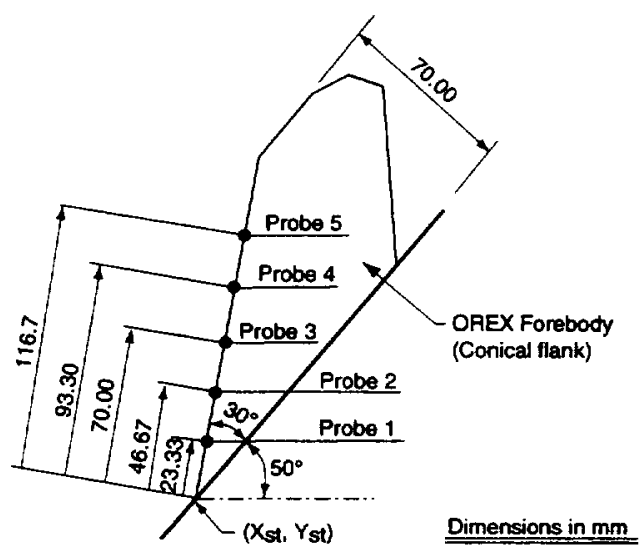

(c) Electrostatic Probe Measurement Locations

Fig. 1 Concluded.

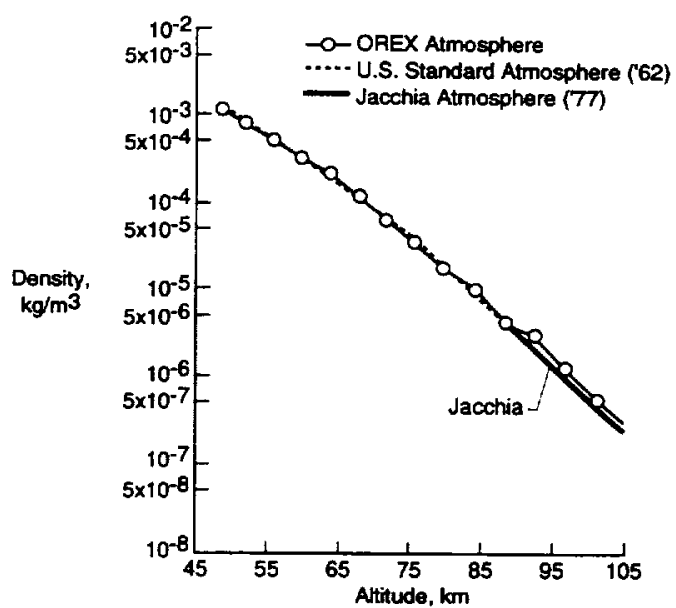

Fig 2. Comparison of OREX atmospheric density (used with Navier-Stokes calculations) with standard values.

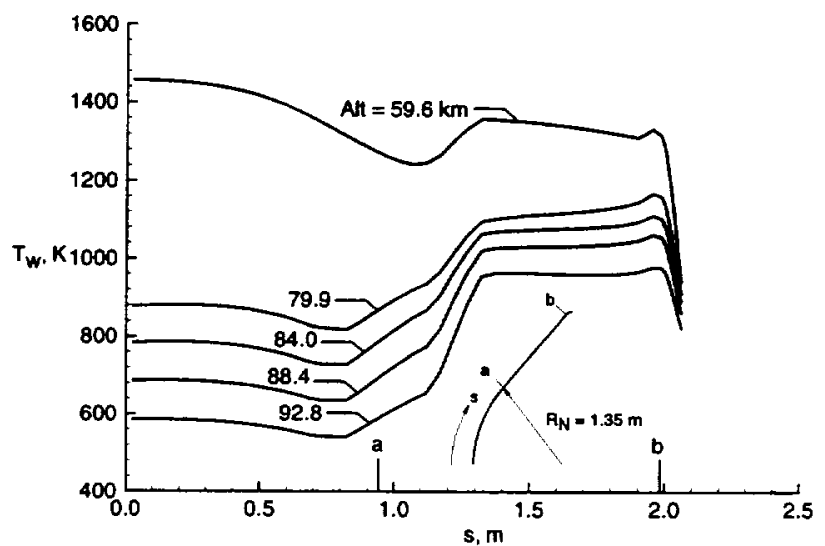

(a) Surface temperature distribution

Fig. 3 Surface temperatures at various altitudes for OREX.

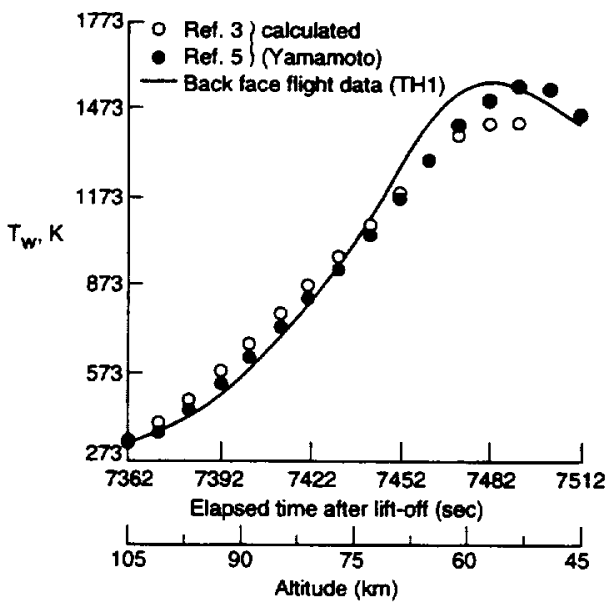

(b) Comparison of $\mathrm{C} / \mathrm{C}$ nose cap stagnation-point temperature history

Fig. 3 Concluded. 


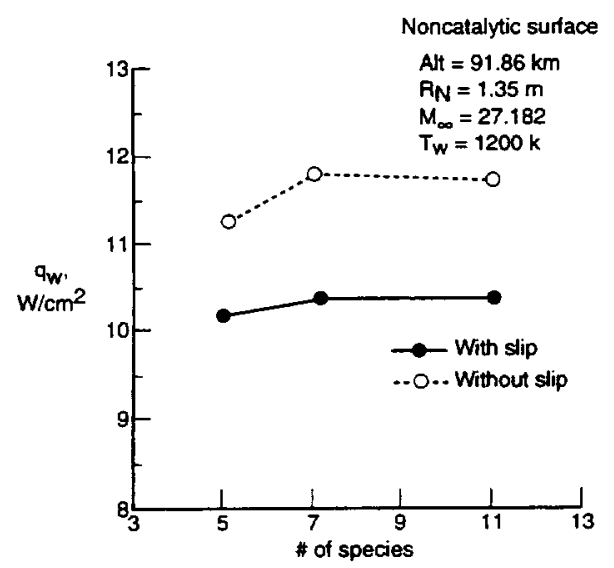

Fig 4. Effect of chemistry model and slip on stagnation heating with thermal nonequilibrium (2-T).

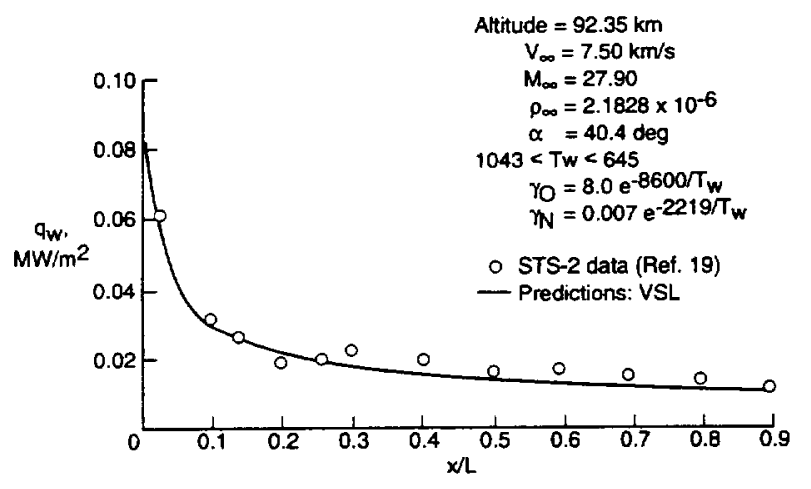

Fig. 5 Comparison of VSL surface heating predictions with STS-2 flight data along the windward center-line plane.

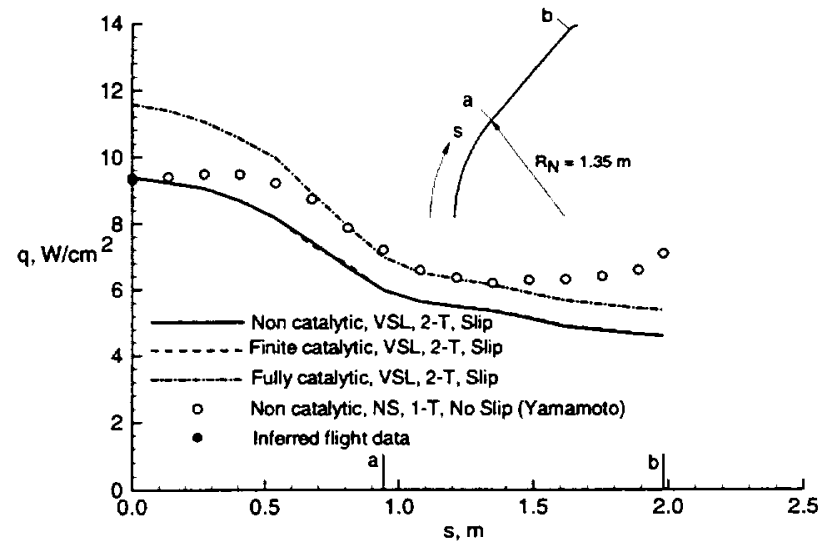

(a) Alt $=92.82 \mathrm{~km}\left(\mathrm{Kn}_{\infty}=0.0086\right)$

Fig. 6 Effect of surface catalytic activity on surface heating rate.

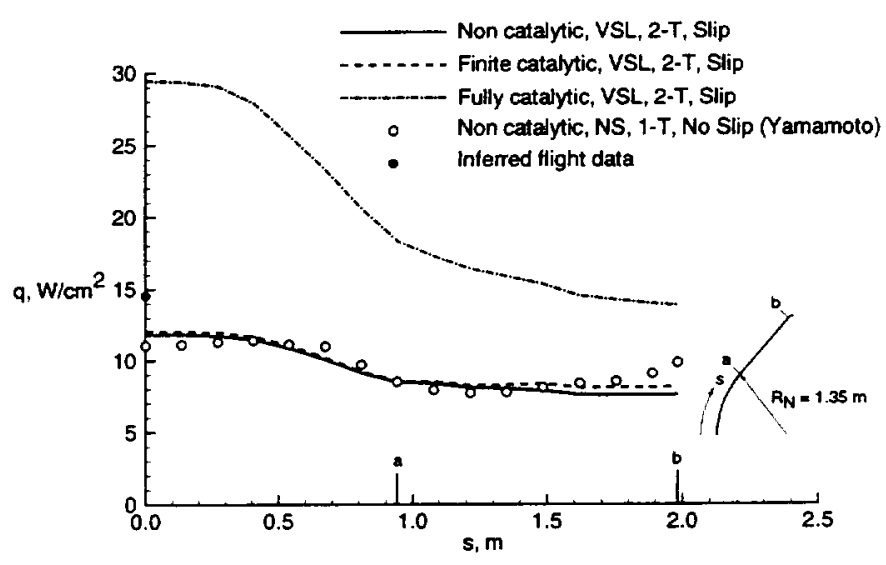

(b) Alt $=84.01 \mathrm{~km}\left(\mathrm{Kn}_{\infty}=\mathbf{0 . 0 0 1 6}\right)$

Fig. 6 Continued.

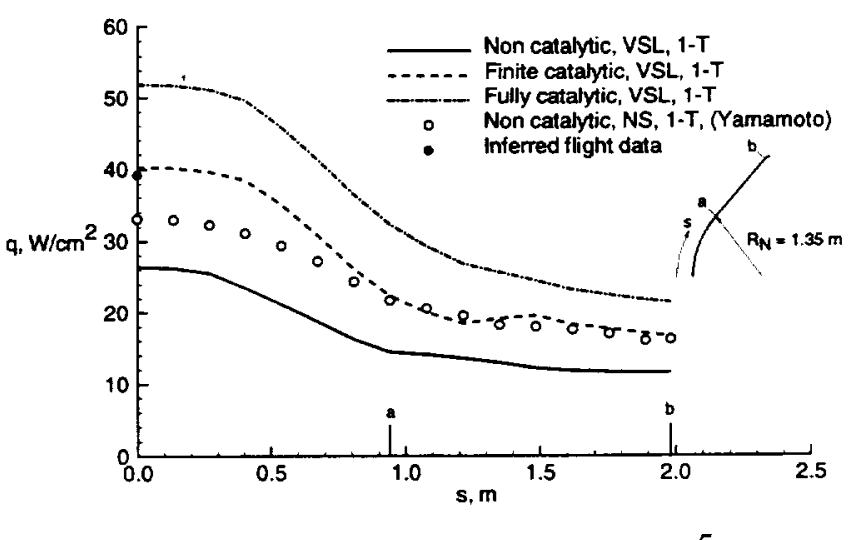

(c) Alt $=59.60 \mathrm{~km}\left(\mathrm{Kn}_{\infty}=7.35 \times 10^{-5}\right)$

Fig. 6 Concluded. 


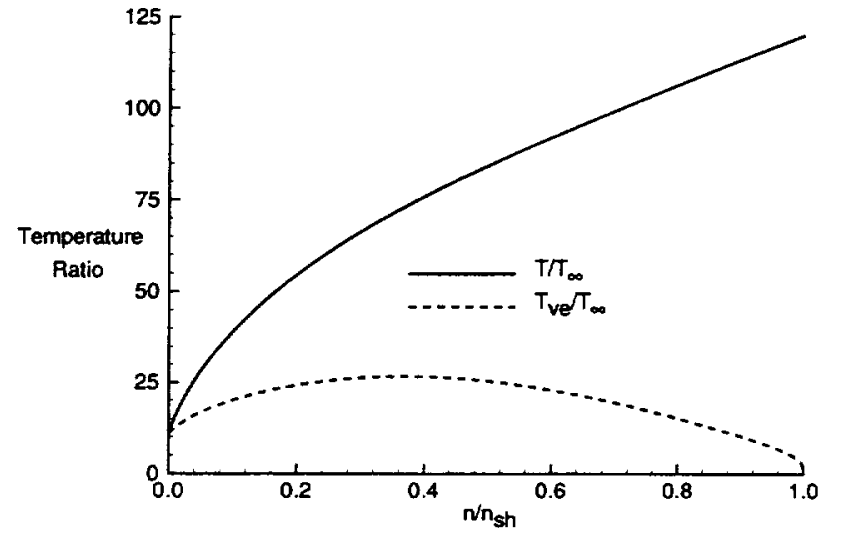

(a) Alt $=92.82 \mathrm{~km}\left(\mathrm{Kn}_{\infty}=0.0086\right)$

Fig. 7 Stagnation temperature profiles (VSL, 2-T, slip).

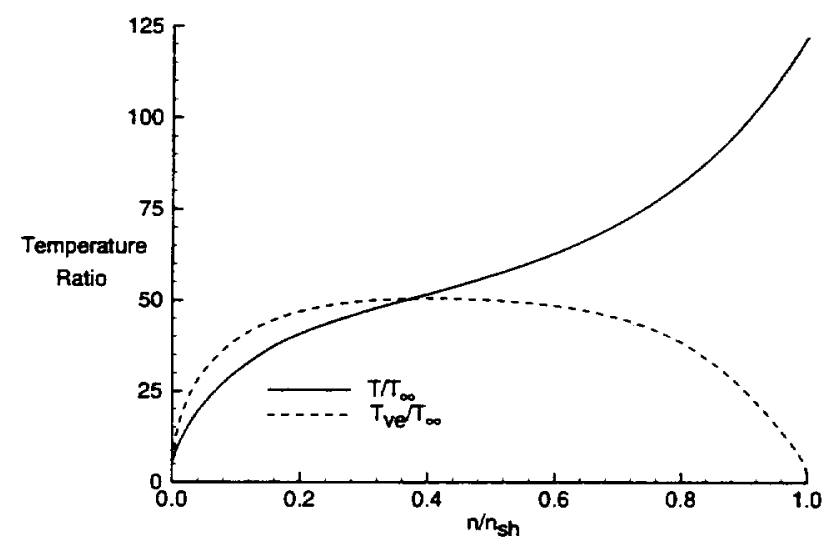

(b) Alt $=84.01 \mathrm{~km}\left(\mathrm{Kn}_{\infty}=0.0016\right)$

Fig. 7 Conluded.

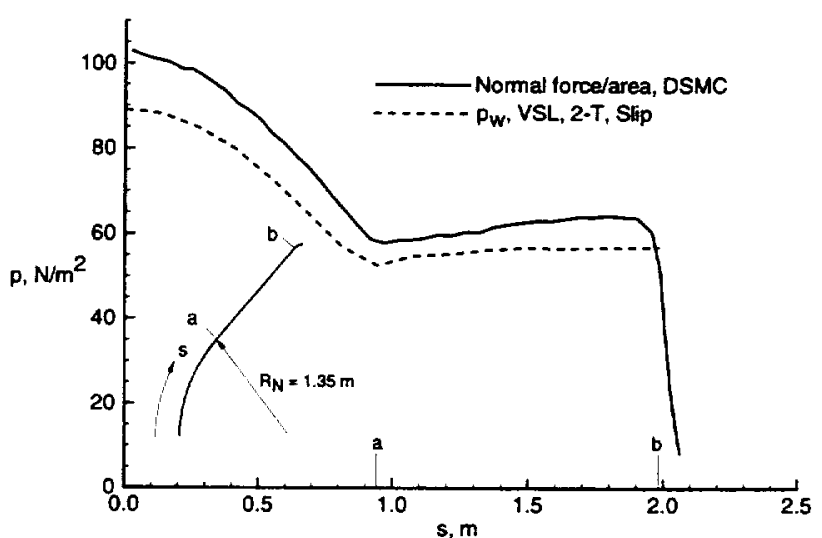

(a) Alt $=92.82 \mathrm{~km}\left(\mathrm{Kn}_{\infty}=0.0086\right)$

Fig.8 Surface pressure distribution.

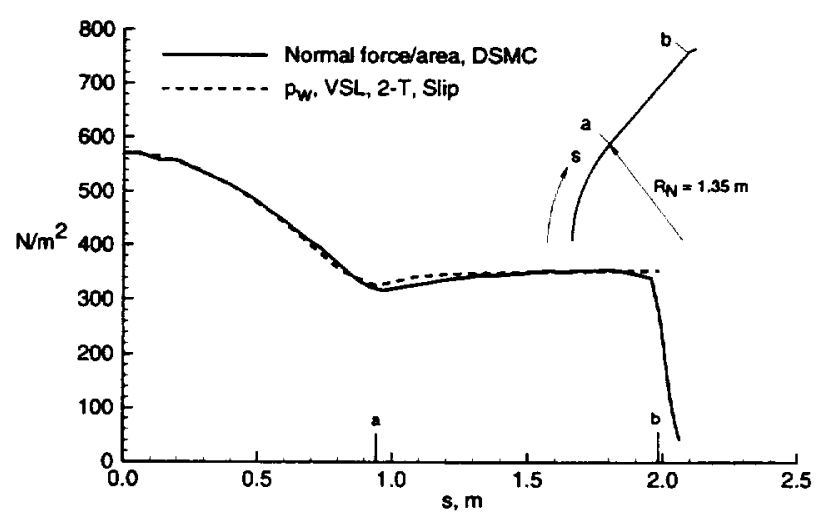

(b) Alt $=84.01 \mathrm{~km}\left(\mathrm{Kn}_{\infty}=0.0016\right)$

Fig. 8 Conluded.

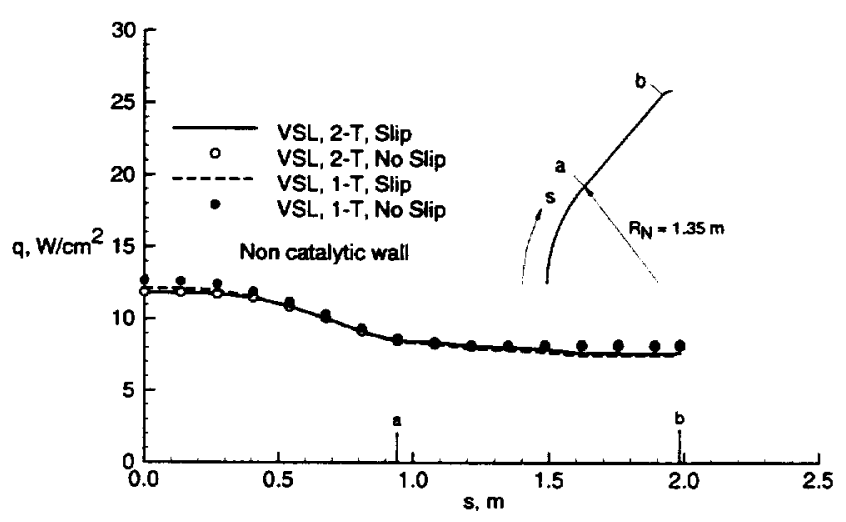

Fig. 9 Predicted surface heating-rate distribution from 1-T and 2-T VSL calculations with and without slip (Alt $=84.01)$. 


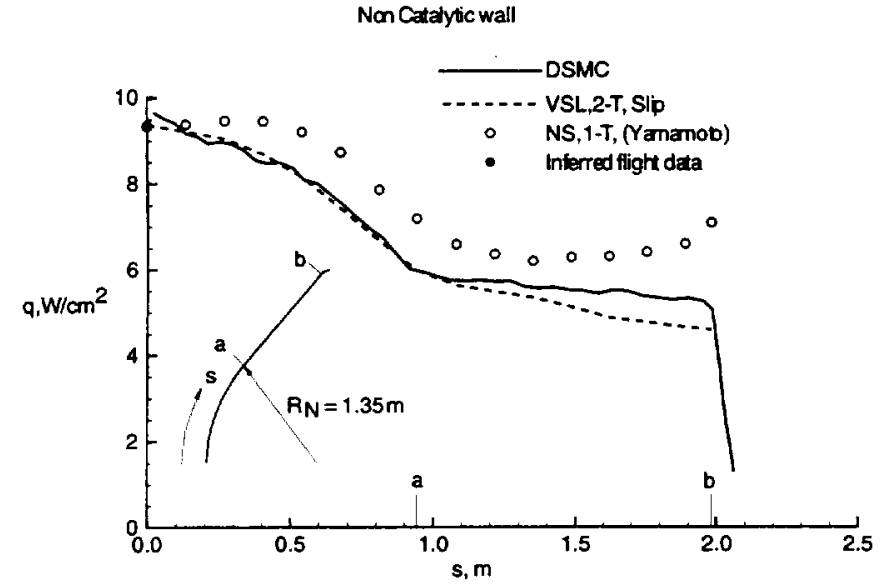

(a) Alt $=92.82 \mathrm{~km}\left(\mathrm{Kn}_{\infty}=0.0086\right)$

Fig. 10 Comparison of surface heating-rate distribution.

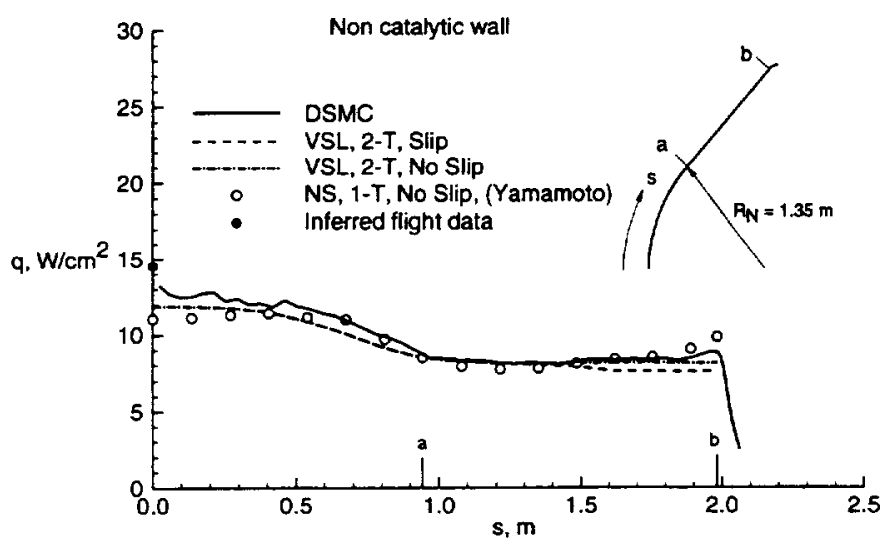

(b) Alt $=84.01 \mathrm{~km}\left(\mathrm{Kn}_{\infty}=0.0016\right)$

Fig. 10 Concluded.

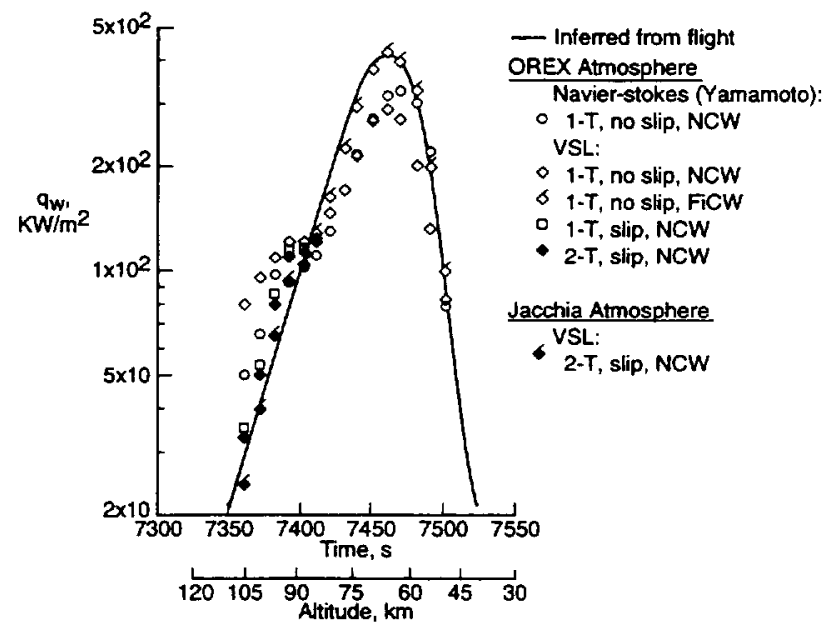

(a) VSL and NS calculations and flight data

Fig. 11 Comparison of predicted stagnation-point heat transfer rates with inferred flight data.

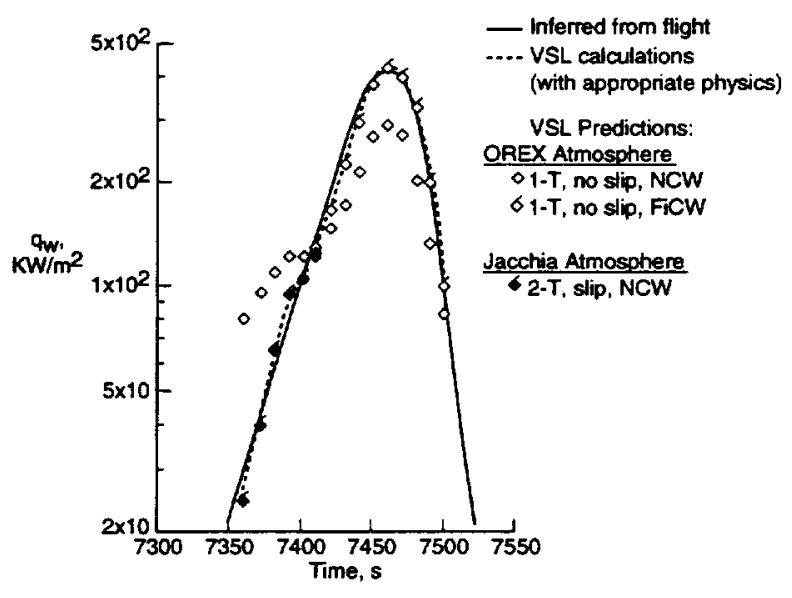

(b) Flight data and VSL results

Fig. 11 Continued.

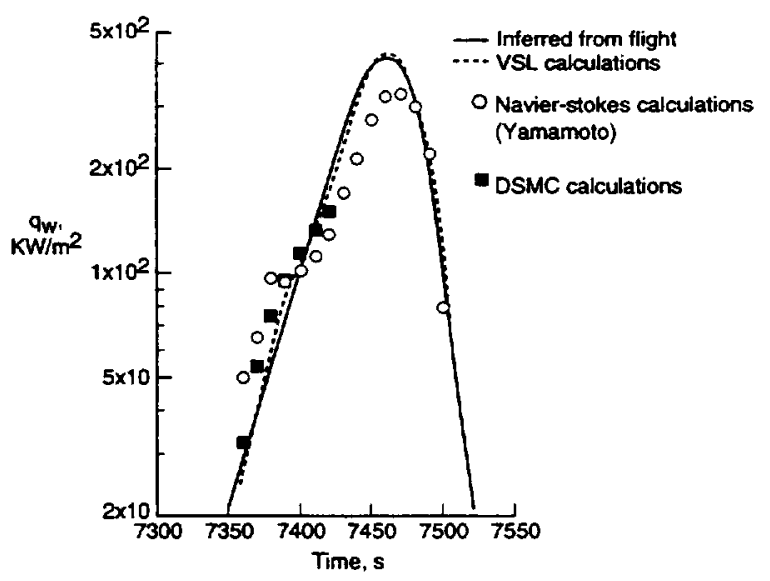

(c) VSL, NS, and DSMC calculations and flight data

Fig. 11 Concluded. 
$\triangle$ Flight data analyzed by 1-temp. CFD

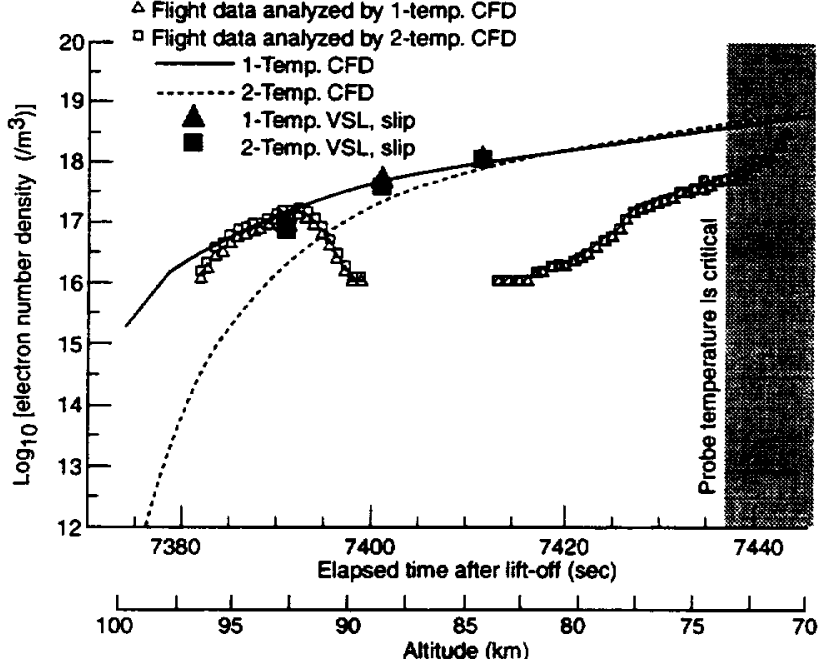

(a) Probe 1 ( $\mathrm{s}=1.8327 \mathrm{~m}, \mathrm{n}=1.1665 \times 10^{-2} \mathrm{~m}$ )

Fig. 12. Electron number density history.

$\triangle$ Flight data anatyzed by 1-temp. CFD

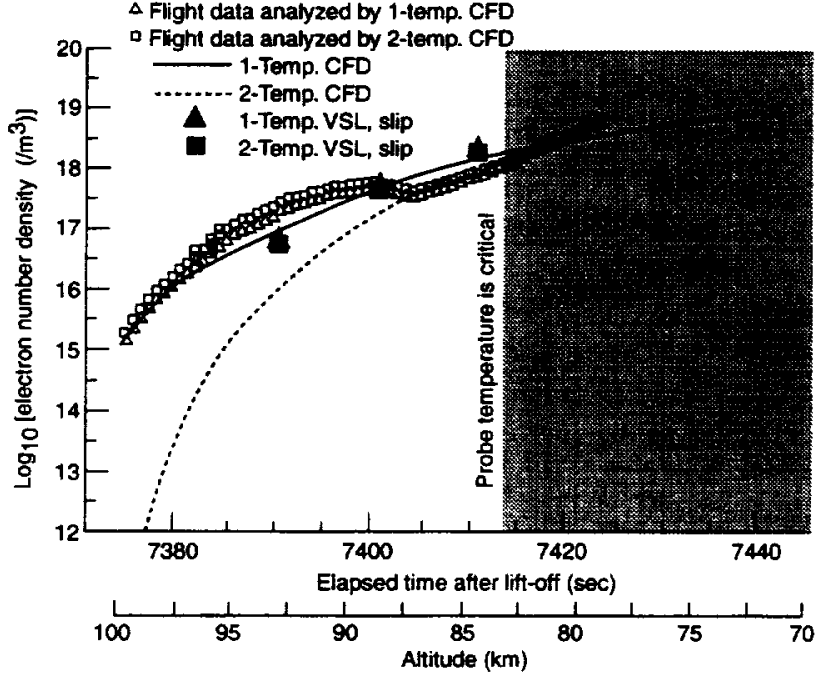

(b) Probe $3\left(\mathrm{~s}=1.8731 \mathrm{~m}, \mathrm{n}=3.50 \times 10^{-2} \mathrm{~m}\right.$ )

Fig. 12. Continued.

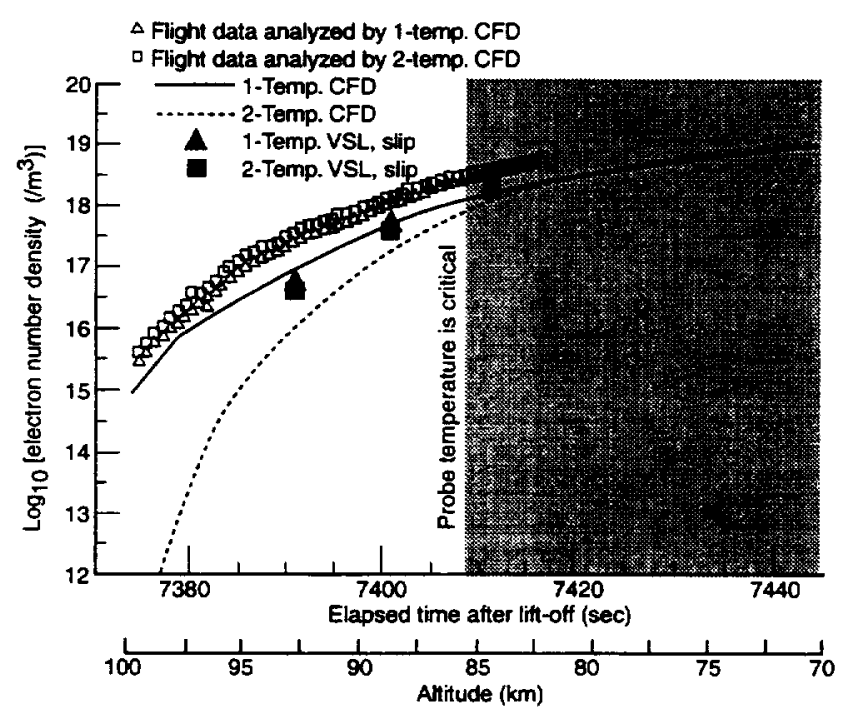

(c) Probe $5\left(\mathrm{~s}=1.9135 \mathrm{~m}, \mathrm{n}=5.8335 \times 10^{-2} \mathrm{~m}\right.$ )

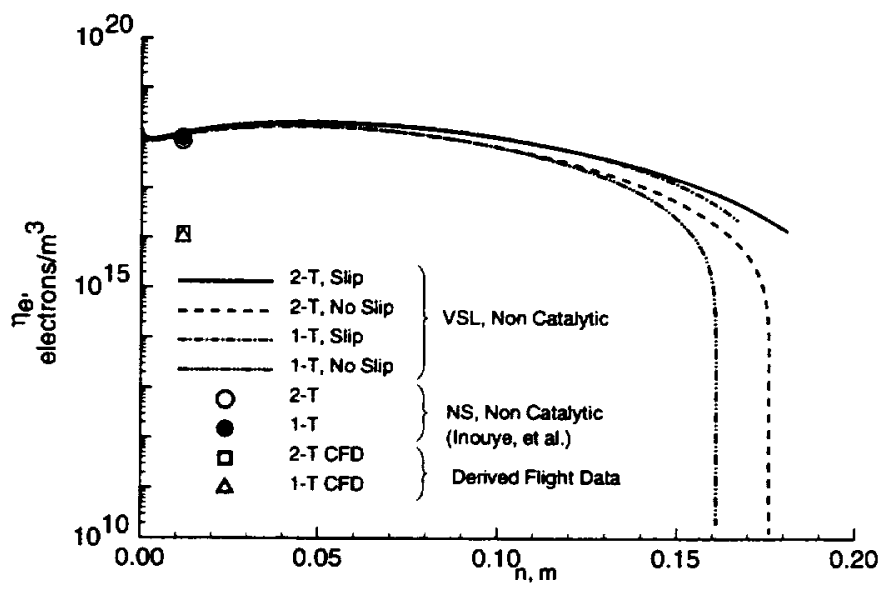

(a) Probe 1 ( $\mathrm{s}=1.8327 \mathrm{~m}, \mathrm{n}=1.1665 \times 10^{-2} \mathrm{~m}$ )

Fig. 13 Comparison of electron number-density profiles

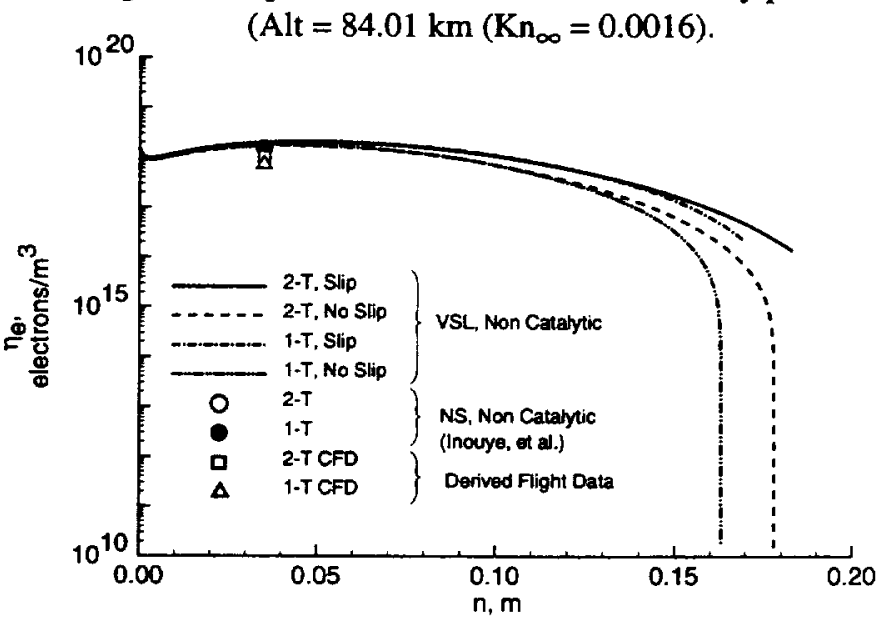

(b) Probe 3 ( $s=1.8731 \mathrm{~m}, \mathrm{n}=3.50 \times 10^{-2} \mathrm{~m}$ )

Fig. 13 Continued.

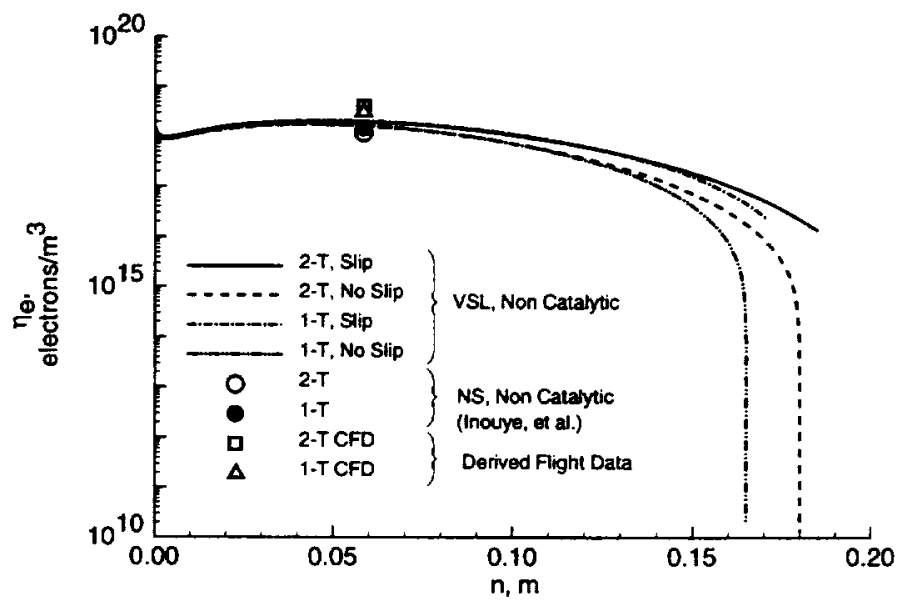

(c) Probe $5\left(\mathrm{~s}=1.9135 \mathrm{~m}, \mathrm{n}=5.8335 \times 10^{-2} \mathrm{~m}\right)$

Fig. 13 Concluded.

Fig. 12. Concluded. 

